\title{
Using Polio GIS drawn maps to increase immunization coverage during mass immunization campaigns in northern Nigeria
}

Mahmud Zubairu Mahmud ( $\nabla$ mahmudisnow@gmail.com )

National Facilitator, World Health Organization, Adamawa state office, Nigeria

Vince Seamans

Bill and Melinda Gates Foundation, Seattle USA

Mahmud Mustapha

National Primary Health Care Development Agency

Research article

Keywords: GIS maps, IPDs micro plans, immunization, polio and GIS dashboard

Posted Date: January 22nd, 2020

DOI: https://doi.org/10.21203/rs.2.21515/v1

License: (1) (i) This work is licensed under a Creative Commons Attribution 4.0 International License.

Read Full License 


\section{Abstract}

Background. Before now, reaching all settlements by vaccinators during mass polio campaigns was a big challenge in northern Nigeria consequent of poor micro plans. This made the attainment of very high immunization coverage which is necessary to interrupt transmission of polio virus in the region difficult. The objective of this study was to devise a means to reach all settlements (BUAs, SSAs, Has) visible on satellite imagery and significantly increase the overall coverage during mass polio immunization campaigns.

Methods. We provide the procedure by which geographic information system GIS drawn maps can be harnessed to improve immunization coverage. We also show the extent to which the maps increase immunization coverage when used to draw vaccination team micro plans in northern Nigeria. The method simply involves the provision of training on map comprehension to relevant health workers (IPDs personnel) followed by the demarcation of the ward polio GIS drawn maps into clusters of settlement areas - commensurate with the total number of vaccination teams allocated to the ward. The maps were then employed to guide IPDs personnel in providing polio immunization services to all households in the ward during the January 2019 mass polio immunization campaign. The study area was a distinct and homogeneous geographical area called Horserizum ward in Hong local government area of Adamawa state, Nigeria and all resident households or members of the communities (totaling 19,698 persons by the recent local census) in ward was the study population.

Results. At the conclusion of the January campaign, the number of settlements in the Ward unreached by health workers (as shown by the GIS dashboard, www.vts.eocng.org) was compared to previous polio immunization campaigns when no GIS maps were used to guide vaccination activities. Results revealed an immunization coverage of $82 \%$ (for January 2019 campaign) versus $43 \%$ during the previous campaign held in December 2018.

Conclusions. The results were statistically significant $(P<0.0000001, t=5.175$.$) and we conclude that,$ using GIS maps to guide vaccination activities (GIS micro planning) has a very significant positive impact on immunization coverage.

\section{Introduction}

The history of mass polio campaigns (Immunization Plus' Days or IPDs for short) dates as far back as 1988 when the world health assembly declared a plan for polio eradication (https://www.who.int/newsroom/detail/25-05-2017). Before then, the disease had ravaged the globe with a burden of over 350,000 paralyzed polio victims every year (https://www.who.int/news-room/fact-sheets/detail/poliomyelitis). The World Health Organization (WHO) provided 2 main strategies as a method of freeing the world completely of polio: namely immunization (of which there are several types) and acute flaccid paralysis AFP surveillance (http://www.emro.who.int/polio/strategy/). Using these strategies, there has been 
remarkable reduction in the number of polio cases worldwide with the disease virtually nonexistence in most countries. Indeed, the only remaining polio endemic countries on the globe as of today (year 2019) according to the WHO are Pakistan, Afghanistan and Nigeria (polioeradication.org/polio-today/polionow/this-week/).

The Nigeria polio problem is a composite of several interwoven factors. These include: noncompliance to immunization, insecurity and vaccination team attitude. Noncompliance to immunization refers to households that are averse to immunization and these abound in the country, particularly in the northern region (Abdulaziz Mohammed et al., 2014). In this part of the country, there still exists many who do not believe in immunization. Consequently, even when presented with vaccines by health workers going house to house during mass polio campaigns, they do not allow their children to be vaccinated. Hence their young children are at a very high risk of polio infection, and as a result the region has found it difficult to interrupt transmission of polio.

Also, in large swaths of the northern region, communal clashes (either herdsmen versus farmers or clashes of ethnic origin) together with armed banditry and terrorism have rendered many communities inaccessible to vaccination teams (WHO, Adamawa state January 2019 IPDs). Pundits argue that until all children trapped in inaccessible communities (settlements) are served polio vaccination, transmission of polio will continue to thrive in Nigeria.

Vaccination team attitude is the (negative) behavior and performance of health workers who work to support polio vaccination. Many public health experts believe that this may be the greatest problem bedeviling the nation's polio program as it cuts across all regions of the country. Vaccination team attitude can have negative impacts on the program in several ways, including: vaccinators deliberately refusing to visit settlements of assignment during campaigns; vaccinators simply dumping polio vaccine while falsely adding the number of names to the tally sheet corresponding to the number of doses poured away; vaccinators colluding with heads of noncompliant households to mark children as vaccinated (a finger mark with indelible marker) when they do not, in fact, receive the vaccine, and so on and so forth.

Despite these problems, the country has nonetheless recorded and continues to record great success in stopping polio (polioeradication.org/where-we-work/nigeria/). Much of the success achieved in polio eradication initiative (PEI) in the country today is attributable to the intervention of government at all levels and many NGOs directly tackling these problems of noncompliance, insecurity and team attitude. One particularly impactful innovation that perhaps can be called the game changer in the history of polio eradication in Nigeria (https://www.slideshare.net/.../how-the-polio-eradication-effort-in-nigeria-led-to-aquest-for-global-geospatial-reference-data), was conceived and implemented by the GPEI partners (mainly WHO, NPHCDA, and the Bill \& Melinda Gates foundation) in 2011. This innovation, called the Vaccination Tracking System (VTS), employs GIS technology to track vaccinators and hence ensures that all settlements are, in fact visited, as well as giving immunization coverage at the end of every mass campaign on a monitoring screen (called the GIS dashboard - vts.eocng.org/Home/About). This 
technology simply involves giving well charged android phones (that collect GPS tracks every 2 minutes) to vaccinators during working hours of any mass polio campaign. At the end of each day's activity, the phone data are uploaded to a central server, and GIS software (ArcMap, ESRI, USA) is used to reveal the GPS locations of where the vaccinators spent the day. The data is also shown on the VTS website (http://vts.eocng.org/) and is then exported to the GIS Dashboard, and contains accurately drawn GIS maps of the entire country, with all human habitations - namely towns, villages and hamlets painstakingly named and identified with geocoordinates (Inuwa Barau, Mahmud Zubairu, et al., 2014). Any human habitations without GPS tracks are classified as "missed" as there is no evidence they were visited/reached by vaccinators. And those with only very few tracks are "poorly reached/covered." Built-up areas (urban) are divided in to a 50 meter grid, and coverage is based on the number of grid squares intersected by a track. Overall coverage is then calculated and displayed on the GIS dashboard during and after polio campaigns (www.vts.eocng.org). Since the introduction of VTS, the progress of the Nigeria polio program has improved significantly and many public health experts believe that eradication is imminent.

Prior to every house to house mass polio immunization campaign in Nigeria a micro plan containing details of all settlements (whether towns, villages or hamlets) within a given region of assignment is prepared by the Ward microplan revision team - a gathering of the traditional leaders, vaccinators and health workers resident in the ward. With a comprehensive line list of settlements within a ward (like Horserizum of Hong LGA of Adamawa, Nigeria), it should not be difficult for vaccinators to cover all areas during immunization campaigns, except for two reasons: namely poor team attitude and/or a faulty micro plan. With intensive supervision coupled with vaccination tracking of health workers, team attitude is surmountable. But what about faulty micro plan? A faulty micro plan implies not all settlements in the ward were actually line-listed in the first place by the ward micro planning revision team. In order to tackle the issue of the faulty micro plan the GPEI partners began the collection of georeferenced settlement data for all wards in Nigeria. (Vince Seaman 2014). The maps were constructed by obtaining all $X$ and $Y$ coordinates of line listed settlements on the existing ward micro plan and viewing them on satellite imagery. Each map is thoroughly scrutinized and any settlements seen on the imagery which were not identified by the initial data collection were flagged and assigned machine or computer generated names - SSA (if they appear like a village) or HA if they look like a hamlet area.

The GIS maps revealed faulty micro plans in nearly every Ward across the country. The maps in most cases contain about $5 \%$ machine-named SSAa and HAs that are totally unknown to ward micro plan revision teams. It therefore comes as no surprise that despite many rounds of mass polio campaigns in Nigeria, many SSAs and HAs are not reached by vaccinators not because they deliberately refuse to do so (team attitude) but due to a faulty micro plan! Experts agree that once vaccinators are tracked (given phone trackers during mass polio $\mathrm{H} 2 \mathrm{H}$ campaigns) and micro plans thoroughly revised such that each and every human habitation in a ward - including machine named SSAs and HAs are assigned locally recognizable names, then, the issue of low immunization coverage due to missed areas (settlements not reached by vaccinators after campaigns) would be over. Such a revision of ward micro plans for mass 
polio campaigns using GIS drawn maps is what is called GIS micro planning and is the bedrock of this study.

\section{Justification}

Analysis of GIS dashboard information over time revealed very poor coverage of settlement areas (particularly hamlet areas) during mass immunization campaigns in Adamawa State. The dashboard uses the presence of GPS tracks in settlements to calculate immunization coverage in a scientific manner \& is freely available on the web at: www.vts.eocng.org. Per the dashboard analytics, any settlements without GPS tracks after the conclusion of mass Polio campaigns are classified as "missed" and those with only very few tracks are "poorly covered". In Horserizum ward of Hong LGA for instance, after the conclusion of the December 2018 IPDs, only $80 \%$ of villages and $43 \%$ of hamlets were reached by vaccinators (the rest were either missed or poorly covered).

Indeed, a total of about 6 hamlet areas (mostly with machine generated names) in the Ward were not covered at all. Machine generated hamlet areas are tiny hamlets (maybe one-man camp or migratory groups) not reflected in the updated ward micro plan list but sighted through satellite imagery and presumed to contain eligible children for vaccination. Despite repeated update of micro plans every round, these hamlet areas have not been identified by any local names hence a difficulty in assigning them to teams for vaccinations. Because resident children in these areas are consistently missed during polio campaigns, they constitute the very high-risk group and are a source of concern to achieving polio eradication in the country. Thus, any innovation to locate and vaccinate these at-risk kids is what the country requires now!

\section{Objective}

The objective of the activity was twofold:

1. Reach all settlements (BUAs, SSAs, HAs) visible on satellite imagery and

2. Significantly increasing the overall coverage

\section{Hypothesis Testing}

The following hypothesis was tested in the study, all at $1 \%$ level of significance;

Null hypothesis: The number of machine generated hamlet areas reached with Polio vaccinations (\& hence immunization coverage) is not contingent on the type of IPDs micro-planning.

Alternate Hypothesis. The number of machine generated hamlet areas reached with Polio vaccinations (\& hence immunization coverage) is contingent on the type of IPDs micro-planning.

\section{Scale Of Implementation}


The activity was piloted in a rural ward of Hong LGA called Horsherizum with a total of 11 vaccination team members partaking.

\section{Methodology}

The production of GIS micro plan for use in the implementation of January 2019 IPDs in Horsherizum ward involves the following steps carried out in a sequential manner viz:

1. Gathering together of the ward micro plan revision team and the provision of map comprehension skills to them by the WHO cluster consultant.

2. Providing locally recognizable names to all machine-named SSAs and HAs appearing on the ward GIS drawn map by the ward micro plan revision team members

3. Ward focal person (WFP) demarcates GIS drawn map (using pen marker to make circumscription) into 7 clusters commensurate with the number of house-to-house teams allocated to the ward for the purpose of IPDs implementation. These are called team work areas.

4. The demarcated team area is further reviewed such that they are approximately of the same total population taking into cognizance the local terrain and distances between settlements within the cluster.

5. 2 days before implementation, each team (headed by a supervisor and containing a vaccinator and a community leader) conducts a tour of the cluster of settlements allocated to her to serve polio vaccination in order to familiarize themselves with the area and to earmark where to begin work on day 1 of implementation.

6. After the logistics tour, team supervisors then divide the assigned cluster of settlements on the ward GIS drawn map into 4 areas - each containing settlements to be visited by the vaccination team members on Days 1-4 of the IPDs. This is the GIS micro plan! Annex A is a copy of Horsherizum GIS micro plan.

7. Each day of implementation, the team supervisor receives a well-charged phone tracker and returns it at the close of business to be uploaded to the VTS server by a GIS technician from eHealth Africa (one of several global polio eradication partners in Nigeria) to reveal tracks of areas visited.

8. Final results (after 4 days of activity) are made available on the GIS dashboard at vts.eocng.org, and any settlements still without tracks are considered missed areas (i.e. not visited by vaccination teams).

\section{Data Collection Instruments}

The following tools were used to collect all relevant information

- Android phones (trackers)

- GIS dashboard

- Latest GIS ward/Team area maps 
- House to house vaccination tally sheets.

\section{Results}

The results below were obtained from the study. They were extracted from both the GIS dashboard and vaccination team tally sheets as at January $31^{\text {st }} 2019$ immediately after conclusion of the January IPDs \& were evaluated in a 'before and after' manner. 'Before' refers to December 2018 IPDs when GIS micro planning was not done and 'after' means January 2019 IPDs when GIS micro planning was done in Horsherizum ward. The procedure for pulling out results from the GIS dashboard is briefly as follows:

1. Search web or go to www.vts.eocng.org

2. Tab on the menu 'geographic coverage' and then pull down month and year of immunization campaign done at the extreme right hand corner.

3. Click on state to pull up state immunization coverage

4. Similarly, pull up LGA immunization coverage by clicking on details and also ward immunization coverage in that fashion

5. Finally, click details under each ward to obtain immunization coverage of all settlement types

Results 1: Performance of android tracking phones - measured as team reporting/teams deployed obtained from the GIS dashboard at www.eocng.org. This number represents the completeness of the tracking data. A value of 100 was obtained in both the 2018 and 2019 round

Results 2: Cumulative immunization coverage of BUAs, SSAs \& HAs - obtained from the GIS dashboard at www.eocng.org.

Results 3: Oral Polio Vaccine, OPV doses used and children immunized - obtained from vaccination team tally sheets

Results 4: Settlements reached and vaccination coverage, urban areas or BUAs- obtained from the GIS dashboard at www.eocng.org.

Results 5: Settlements reached and vaccination coverage, small settlement areas or SSAs - obtained from the GIS dashboard at www.eocng.org.

Results 6: Settlements reached and vaccination coverage, hamlet areas or HAs - obtained from the GIS dashboard at www.eocng.org.

\section{Discussion}

The figure 100 reported in results 1 as the value of phones implies that majority of the tracking phones used during both campaigns (year 2018 and 2019) had no issues: none switched off on its own in the field during usage and all successfully uploaded their tracks after close of business every day to the GIS 
dashboard. Therefore, any settlements seen without tracks in the study whether BUAs, SSAs or HAs is not because any phones malfunctioned but because no vaccinator visited the area.

Results 2 shows that the immunization coverage for all types of settlements were increased as a consequence of GIS micro planning. A critical look at the figures, however, suggests that the effect is more pronounced on the coverage of HAs. For instance, before GIS micro planning, immunization coverage of HAs in Horsherizum was a dismal $43 \%$. After GIS micro plans were developed and used (January 2019 IPDs), it shot up to a whopping $82 \%$ ! On the other hand, percentage immunization coverage of BUAs before and after was 71 and $74 \%$ respectively - just a very little increment. Unlike HAs, BUAs and SSAs are conspicuous areas of human habitations. They are often very well known to every member of the vaccinating team and usually areas first listed on conventional walk through micro plans as areas to be covered by any team. It is therefore not surprising that immunization coverage of BUAs and SSAs is least affected by GIS micro planning. The truth of the matter is, once a settlement is correctly listed and assigned a locally recognizable name (as with all SSAs on GIS maps or walk through micro plans), any vaccinator should reach it if provided the right motivation! Thus, a simple conclusion that can be drawn from results 2 is that, the micro plans used by teams in Horsherizum ward during January 2019 IPDs allowed them to reach more hamlet areas than that employed in December 2018 (conventional walk through micro plans). But is this 'statistically' significant?

Results 3 indicates that more children and accordingly more doses of vaccines were used in Horsherizum in January 2019 when GIS micro planning was done compared to December 2018 when it was not. This is totally in agreement with immunization coverage seen in results 2 above as the doses of vaccine used must be commensurate with number of children immunized. It is a testimony of good data quality and the fidelity of GIS micro planning in increasing immunization coverage during mass immunization campaigns.

Results 4 suggest that there is no need doing GIS micro planning in order for vaccinators to cover BUAs properly. As a matter of fact, there isn't much difference in immunization coverage when GIS micro plans were used compared to when it was not. As already mentioned in paragraph two above, this is not surprising and only implies that, to cover BUAs properly during IPDs, all that is required is supervision and 'team motivation'. Indeed, statistically, at $1 \%$ level of significance, there's no statically significant difference in the 2 immunization coverage results and we conclude that use of GIS drawn maps for micro planning appears to have no effect on coverage of BUAs.

A cursory look at results 5 reveals that a total of 4 small settlements - namely KWACHAFAM, MAIRANAWO, MAKERA JAURO IBRAHIM \& WAFAATI that were not reached at all by vaccinators in 2018 were touched in January 2019 when GIS micro plans were employed. Although it is significant or important for the polio eradication that these five settlements are probably covered for the first time, analysis of the entire immunization coverage data for small settlement areas (SSA) statistically using the students T-test and at 1\% level of significance shows no significant difference between 2018 and 2019 immunization coverage data though. Thus, using GIS micro plans does not appear to improve 
immunization coverage for SSAs. Indeed, as earlier postulated, once a settlement is correctly line-listed and assigned a locally recognizable name (as with all SSAs on GIS maps or walk through micro plans), any vaccinator should reach it if provided the right motivation!

As regards coverage of HAs, GIS micro planning has a profound effect. Aside from facilitating the vaccination team's visit of several HAs (a total of seven HAs that were completely not visited in 2018 saw vaccinators in 2019 possibly for the first time), many HAs that were hitherto poorly covered (i.e in 2018) also had their coverage tremendously increased. And furthermore, statistical analysis of immunization coverage results depicted in results 6 as shown in the table below using the students $T-$ test revealed a significant difference between immunization coverage of HAs in 2018 versus 2019. This strongly suggests the rejection of the 'Null hypotheses. Thus, it appears the number of machine generated hamlet areas HAs, reached with Polio vaccinations (\& hence immunization coverage) is contingent on the type of IPDs micro-planning. Indeed, by the results statistics, the probability that all HAs were reached in the Horsherizum ward during January round of IPDs when GIS micro planning was used for implementation is about 1 in a 10,000 due to chance!

\section{Conclusions/recommendations}

We conclude that when GIS micro planning was undertaken in January 2019, the quality of immunization as measured by immunization coverage - particularly of hamlet areas - was much better than in December 2018 when there was no GIS micro planning. Statistical analysis revealed that there is indeed significant difference between immunization coverage in Horsherizum ward' before and after the study. And that that difference was not due to 'chance'! As majority of Nigeria's underserved population in terms of the provision of health services including immunization live in hamlet areas coupled with the fact that, the settlements most often missed on the GIS dashboard after vaccination team tracking and reported by eHealth Africa (a polio eradication partner in Nigeria) are hamlet areas, any innovation to enhance the ability of vaccinators to find and reach them is pertinent.

It is therefore strongly recommended that GIS micro planning be adopted by WHO Adamawa as a panacea to reaching the high number of hamlet areas reported as missed areas by VTS after rounds of mass Polio campaign in northern Nigeria.

Relevance of study: The research shall form the way and manner of reaching all human habitations with OPV during IPDs by the GPEl partners (NPHCDA, WHO, NGO partners).

Study limitations: The applicability of results of study are limited to States of Nigeria with GIS drawn maps.

\section{Abbreviations}

1. GIS - Geographic Information System

2. BUAs - Built Up Areas (means big towns or communities that are part of a big town) 
3. SSAs - Small Settlement Areas (refers to small villages)

4. HAs - Hamlet areas (refers to scattered and very small camps)

5. IPDs - Immunization Plus Days'

6. WHO - World Health Organization

7. AFP - Acute Flaccid Paralysis

8. PEI - Polio Eradication Initiative

9. NGOs - Non Governmental Organization

10. GPEI - Global Polio Eradication Initiative

11. NPHCDA - National Primary Health Care Development Agency

12. VTS - Vaccination Tracking System

13. GPS - Global Positioning System

14. WFP - Ward Focal Person

15. OPV - Oral Polio Vaccine

\section{Declarations}

Ethics approval and consent to participate: No consent is required to initiate the study

Consent for publication: No consent is required from any quarters

Availability of data and material: All relevant and necessary data implied in this study are available at the GIS dashboard. This can be accessed at www.vts.eocng.org

Competing interests: There are no competing interests what so ever!

Funding: Personal savings of the principal author was used for the study

Author's contributions

Acknowledgements: Profound gratitude is to God Almighty for giving the good health to conduct this research. It was undertaken in a region with serious security challenges in the form of BOKO HARAM terrorism and so, may God be praised for sparing our lives till the end of the research.

Aside from this, thanks to the World Health Organization (WHO) for providing the enabling environment to conduct the research. No doubt the research would not have been possible without my engagement as an SSA contract holder by the WHO.

Profound gratitude also to the following people for their comments, suggestions and imputs into the design of the study: Mr. Kebba Toure of the World Health Organization, Regional office, Congo Brazzaville for reviewing the initial research proposal; Mr. Joseph Yamtu, an astute WHO LGA-facilitator 
for his constructive criticisms; And finally, the entire member of staff of the health department of Hong LGA in Adamawa state Nigeria for thoroughly supervising the field component of the research.

\section{References}

1. Inuwa BarauMahmud ZubairuMichael N. Mwanza Vincent Y. Seaman. Improving Polio Vaccination Coverage in Nigeria Through the Use of Geographic Information System Technology. The Journal of Infectious Diseases, Volume 210, Issue suppI_1, 1 November 2014, Pages S102-S110

2. Abdulaziz Mohammed, Kabir Sabitu, Patrick Nguku. Characteristics of persons refusing oral polio vaccine during the immunization plus days - Sokoto, Nigeria 2011. The Pan African Medical Journal. 2014;18 (Supp 1):10. doi:10.11604/pamj.supp.2014.18.1.418

3. Vince Seaman 2914, How the polio eradication effort in Nigeria led to a quest for global geospatial reference data. https://www.slideshare.net/.../how-the-polio-eradication-effort-in-nigeria-led-to-aquest-for-global-geospatial-reference-data

\section{Tables}

Table 1. Settlements reached and vaccination coverage, urban areas or BUAs only.

\begin{tabular}{|l|l|l|l|}
\hline Settlement Name & $\begin{array}{l}\text { Settlement } \\
\text { Type }\end{array}$ & $\begin{array}{l}\text { Cumulative \% Visited Dec } \\
2018\end{array}$ & $\begin{array}{l}\text { Cumulative \% Visited Jan } \\
2019\end{array}$ \\
\hline Biri Mullah & Urban Area & 70 & 88.46 \\
\hline Jauro Muazu & Urban Area & 70 & 70 \\
\hline Likuku & Urban Area & 70 & 80.6 \\
\hline Makera Jauro Hussaini & Urban Area & 76 & 82 \\
\hline $\begin{array}{l}\text { Mustapha Yakubu } \\
\text { Mukhtar }\end{array}$ & Urban Area & 70 & 71.74 \\
\hline
\end{tabular}

Table 2. Settlements reached and vaccination coverage, small settlement areas or SSAs only. 


\begin{tabular}{|c|c|c|c|}
\hline Settlement Name & $\begin{array}{l}\text { Settlement } \\
\text { Type }\end{array}$ & $\begin{array}{l}\text { Cumulative \% Visited Dec } \\
2018\end{array}$ & $\begin{array}{l}\text { Cumulative \% Visited Jan } \\
2019\end{array}$ \\
\hline Barkari I & $\begin{array}{l}\text { Small } \\
\text { Settlement }\end{array}$ & 100 & 100 \\
\hline Barkari II & $\begin{array}{l}\text { Small } \\
\text { Settlement }\end{array}$ & 100 & 100 \\
\hline Dadawaloji & $\begin{array}{l}\text { Small } \\
\text { Settlement }\end{array}$ & 100 & 100 \\
\hline Gangni B & $\begin{array}{l}\text { Small } \\
\text { Settlement }\end{array}$ & 100 & 100 \\
\hline Garari & $\begin{array}{l}\text { Small } \\
\text { Settlement }\end{array}$ & 100 & 100 \\
\hline Jaba Banshika & $\begin{array}{l}\text { Small } \\
\text { Settlement }\end{array}$ & 100 & 100 \\
\hline Jabba Dziga Yerima & $\begin{array}{l}\text { Small } \\
\text { Settlement }\end{array}$ & 100 & 100 \\
\hline Jabba Hosheri & $\begin{array}{l}\text { Small } \\
\text { Settlement }\end{array}$ & 100 & 100 \\
\hline Kwanchafarm & $\begin{array}{l}\text { Small } \\
\text { Settlement }\end{array}$ & 0 & 100 \\
\hline Luga & $\begin{array}{l}\text { Small } \\
\text { Settlement }\end{array}$ & 100 & 100 \\
\hline Madagali & $\begin{array}{l}\text { Small } \\
\text { Settlement }\end{array}$ & 100 & 100 \\
\hline Mairanawo & $\begin{array}{l}\text { Small } \\
\text { Settlement }\end{array}$ & 0 & 100 \\
\hline Makera Jauro Ibrahim & $\begin{array}{l}\text { Small } \\
\text { Settlement }\end{array}$ & 0 & 100 \\
\hline Matafash & $\begin{array}{l}\text { Small } \\
\text { Settlement }\end{array}$ & 100 & 100 \\
\hline Mombol Krabiri & $\begin{array}{l}\text { Small } \\
\text { Settlement }\end{array}$ & 100 & 100 \\
\hline Mombol Ndlabiri & $\begin{array}{l}\text { Small } \\
\text { Settlement }\end{array}$ & 100 & 100 \\
\hline Tudu & $\begin{array}{l}\text { Small } \\
\text { Settlement }\end{array}$ & 100 & 100 \\
\hline $\begin{array}{l}\text { Unguwan Jauro } \\
\text { Martine }\end{array}$ & $\begin{array}{l}\text { Small } \\
\text { Settlement }\end{array}$ & 100 & 100 \\
\hline Wafaati & Small & 0 & 100 \\
\hline
\end{tabular}




\begin{tabular}{|l|l|l|l|} 
& Settlement & & \\
\hline Wuro Garba & $\begin{array}{l}\text { Small } \\
\text { Settlement }\end{array}$ & 100 & 100 \\
\hline
\end{tabular}

Table 3. Settlements reached and vaccination coverage, hamlet areas or HAs only. 


\begin{tabular}{|c|c|c|c|}
\hline Settlement Name & Settlement Type & Cumulative \% Visited Dec 2018 & Cumulative \% Visited Jan 2019 \\
\hline Arndo Fulani & Hamlet Area & 80 & 80 \\
\hline Arndu & Hamlet Area & 100 & 100 \\
\hline Chakamaje & Hamlet Area & 100 & 100 \\
\hline Chirali & Hamlet Area & 80 & 100 \\
\hline Dulhuba & Hamlet Area & 100 & 100 \\
\hline HA_1 & Hamlet Area & 50 & 100 \\
\hline HA_10 & Hamlet Area & 100 & 100 \\
\hline HA_12 & Hamlet Area & 50 & 50 \\
\hline HA_14 & Hamlet Area & 100 & 100 \\
\hline HA_18 & Hamlet Area & 50 & 100 \\
\hline HA_19 & Hamlet Area & 50 & 50 \\
\hline HA_2 & Hamlet Area & 100 & 100 \\
\hline HA_21 & Hamlet Area & 100 & 100 \\
\hline HA_23 & Hamlet Area & 50 & 100 \\
\hline HA_24 & Hamlet Area & 50 & 50 \\
\hline HA_25 & Hamlet Area & 100 & 100 \\
\hline HA_3 & Hamlet Area & 100 & 100 \\
\hline HA_4 & Hamlet Area & 100 & 100 \\
\hline HA_5 & Hamlet Area & 0 & 100 \\
\hline HA_6 & Hamlet Area & 0 & 0 \\
\hline HA_7 & Hamlet Area & 50 & 100 \\
\hline HA_8 & Hamlet Area & 50 & 100 \\
\hline HA_9 & Hamlet Area & 100 & 100 \\
\hline Kesure & Hamlet Area & 50 & 100 \\
\hline Kwaghkba & Hamlet Area & 0 & 100 \\
\hline Kwatsin & Hamlet Area & 100 & 100 \\
\hline Lafakin & Hamlet Area & 0 & 100 \\
\hline Luga Fulani & Hamlet Area & 40 & 80 \\
\hline Naderi & Hamlet Area & 0 & 66.67 \\
\hline Nassarawo & Hamlet Area & 50 & 66.67 \\
\hline Njaringa & Hamlet Area & 100 & 100 \\
\hline Public Well & Hamlet Area & 50 & 100 \\
\hline Sikali & Hamlet Area & 50 & 100 \\
\hline Tsohon Gari & Hamlet Area & 0 & 100 \\
\hline Ungwa Murulei & Hamlet Area & 100 & 100 \\
\hline Vindi Abache & Hamlet Area & 0 & 88.89 \\
\hline
\end{tabular}




\begin{tabular}{|l|l|l|l|} 
Wuro Baba lya & Hamlet Area & 100 & 100 \\
\hline Wuro Babeyo & Hamlet Area & 66.67 & 100 \\
\hline Wuro Bali & Hamlet Area & 0 & 60 \\
\hline Wuro Biriji & Hamlet Area & 100 & 100 \\
\hline Wuro Gau & Hamlet Area & 100 & 100 \\
\hline Wuro Jabbe & Hamlet Area & 50 & 100 \\
\hline Wuro Mbaya & Hamlet Area & 100 & 100 \\
\hline Zhir & Hamlet Area & 100 & 100 \\
\hline
\end{tabular}

t-Test: Paired Two Sample for Means

\begin{tabular}{lll}
\hline & Variable 1 & Variable 2 \\
\hline Mean & 90.7325 & 64.01523 \\
\hline Variance & 429.4465448 & 1419.421 \\
\hline Observations & 44 & 44 \\
\hline Pearson Correlation & 0.433007868 & \\
\hline Hypothesized Mean Difference & 0 & \\
\hline df & 43 & \\
\hline$t$ Stat & 5.175110799 & \\
\hline $\mathrm{P}(\mathrm{T}<=\mathrm{t})$ one-tail & $2.84685 \mathrm{E}-06$ & \\
\hline $\mathrm{t}$ Critical one-tail & 2.416250129 & \\
\hline $\mathrm{P}(\mathrm{T}<=\mathrm{t})$ two-tail & $5.6937 \mathrm{E}-06$ & \\
\hline $\mathrm{t}$ Critical two-tail & 2.695102079 & \\
\hline
\end{tabular}

\section{Figures}

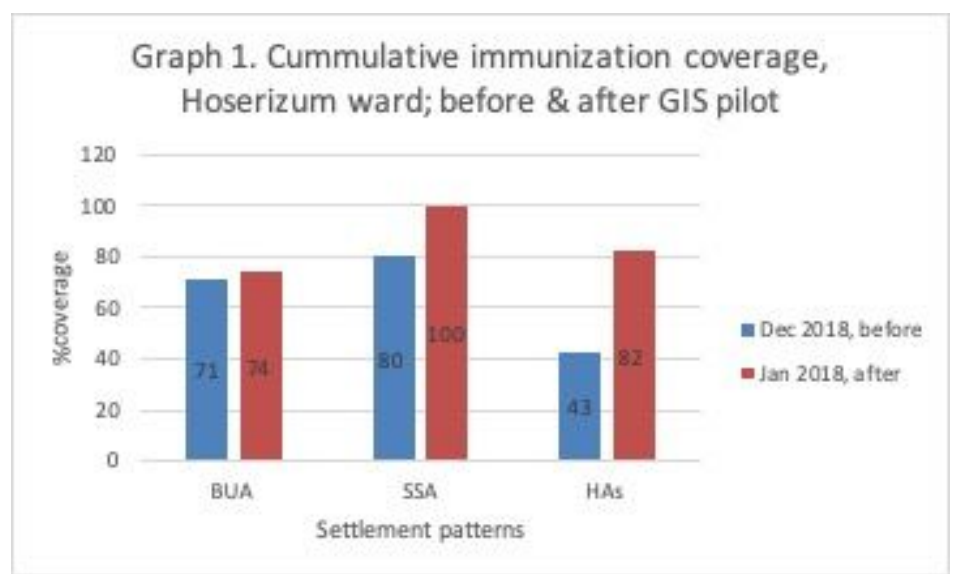


Figure 1

Graph 1. Cumulative immunization coverage of BUAs, SSAs and HAs in Horsherizum 'before' and 'after'

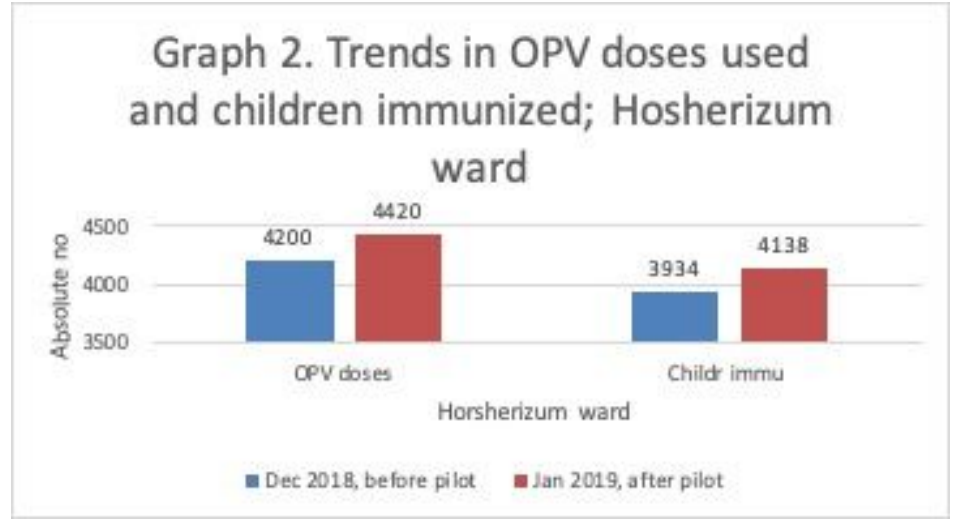

Figure 2

Graph 2. Trends Oral Polio Vaccine (OPV) doses used and children immunized; Horsherizum ward 